\title{
Improved detection of Pneumocystis jirovecii in upper and lower respiratory tract specimens from children with suspected pneumocystis pneumonia using real-time PCR: a prospective study
}

Catherine M Samuel $^{1 *}$, Andrew Whitelaw ${ }^{1}$, Craig Corcoran² ${ }^{2}$ Brenda Morrow ${ }^{3}$, Nei-Yuan Hsiao ${ }^{2}$, Marco Zampoli ${ }^{3}$ and Heather J $\mathrm{Zar}^{3}$

\begin{abstract}
Background: Pneumocystis pneumonia (PCP) is a major cause of hospitalization and mortality in HIV-infected African children. Microbiologic diagnosis relies predominantly on silver or immunofluorescent staining of a lower respiratory tract (LRT) specimens which are difficult to obtain in children. Diagnosis on upper respiratory tract (URT) specimens using PCR has been reported useful in adults, but data in children are limited. The main objectives of the study was (1) to compare the diagnostic yield of PCR with immunofluorescence (IF) and (2) to investigate the usefulness of upper compared to lower respiratory tract samples for diagnosing PCP in children.
\end{abstract}

Methods: Children hospitalised at an academic hospital with suspected PCP were prospectively enrolled. An upper respiratory sample (nasopharyngeal aspirate, NPA) and a lower respiratory sample (induced sputum, IS or bronchoalveolar lavage, BAL) were submitted for real-time PCR and direct IF for the detection of Pneumocystis jirovecii. A control group of children with viral lower respiratory tract infections were investigated with PCR for PCP. Results: 202 children (median age 3.3 [inter-quartile range, IQR 2.2 - 4.6] months) were enrolled. The overall detection rate by PCR was higher than by IF [180/349 (52\%) vs. 26/349 (7\%) respectively; $p<0.0001]$. PCR detected more infections compared to IF in lower respiratory tract samples [93/166 (56\%) vs. 22/166 (13\%); p < 0.0001] and in NPAs [87/183 (48\%) vs. 4/183 (2\%); $p<0.0001]$. Detection rates by PCR on upper (87/183; 48\%) compared with lower respiratory tract samples $(93 / 166 ; 56 \%)$ were similar $(\mathrm{OR}, 0.71 ; 95 \% \mathrm{Cl}, 0.46-1.11)$. Only $2 / 30$ (6.6\%) controls were PCR positive.

Conclusion: Real-time PCR is more sensitive than IF for the detection of $P$. jirovecii in children with PCP. NPA samples may be used for diagnostic purposes when PCR is utilised. Wider implementation of PCR on NPA samples is warranted for diagnosing PCP in children.

\section{Background}

Pneumocystis pneumonia (PCP), caused by Pneumocystis jirovecii, is an important opportunistic infection in HIVinfected children $[1,2]$. The incidence of PCP in developed countries has declined since the introduction of highly active anti-retroviral therapy and use of chemoprophylaxis. However, PCP remains a major cause of

\footnotetext{
* Correspondence: cath_samuel@hotmail.com

'Division of Medical Microbiology, University of Cape Town and National Health Laboratory Service, Cape Town, South Africa

Full list of author information is available at the end of the article
}

hospitalization and mortality in HIV-infected children in low or middle income countries, [1,3-5] with reported incidence rates of $10-49 \%,[1,3,6]$ and in-hospital casefatality rates of $20-63 \%[1,3,4,6]$. Apart from HIV infection, there are other factors that predispose children to developing PCP including malnutrition, other immune deficiencies or HIV exposure. Untreated, the case fatality rate in children with PCP approximates $100 \%[1,3,4,6]$. However, diagnosis can be difficult as clinical and radiological findings are non-specific.

\section{Biomed Central}

(c) 2011 Samuel et al; licensee BioMed Central Ltd. This is an Open Access article distributed under the terms of the Creative Commons Attribution License (http://creativecommons.org/licenses/by/2.0), which permits unrestricted use, distribution, and reproduction in any medium, provided the original work is properly cited. 
Therefore, a rapid, accurate laboratory diagnosis is important for timely use of appropriate medication.

Detection of $P$. jirovecii is hampered by the lack of a sustainable in-vitro culture method [7]. Standard laboratory diagnostic methods are microscopic examination of a lower respiratory tract sample with Gomori Grocott's methenamine silver nitrate stain or the more sensitive immunofluorescence assay (IF) [8] on bronchoalveolar lavage (BAL) or induced sputum (IS) specimens. Using microscopy, the yield from IS has been reported to be similar compared to that from BAL [9]. However, sputum induction in children is not widely performed, requires staff trained to do the procedure and may result in clinical deterioration or nosocomial transmission of respiratory pathogens. Diagnosis using a noninvasive sample such as a nasopharyngeal aspirate (NPA) is, therefore, desirable.

The clinical sensitivity from a NPA has been reported to be low and variable when microscopy is utilised $[4,5,10]$. The development of polymerase chain reaction (PCR) techniques has provided a more reliable diagnostic method. In adult studies, PCR is as specific as and more sensitive than microscopy for diagnosis when performed on respiratory specimens, including oral washes $[7,11-21]$. In a study of oropharyngeal washes from HIV-infected adult patients, $P$. jirovecii DNA-amplification had a sensitivity of $44 \%$ using a nested PCR protocol compared to trans-bronchial biopsy, [16] increasing to $90 \%$ when touch-down real-time PCR was utilised $[7,11]$. Real-time PCR also allows for quantification of the organism load and with application of cutoff values, could improve the specificity by distinguishing between colonization and infection [13].

The aims of this study were (1) to compare a real-time quantitative PCR assay with IF for the diagnosis of PCP in children and (2) to evaluate the reliability of PCR for the diagnosis of PCP in upper compared to lower respiratory tract secretions.

\section{Methods}

\section{Participants}

Consecutive children $(<14$ years old) with suspected PCP, hospitalized at Red Cross War Memorial Children's Hospital, Cape Town, South Africa, were enrolled from November 2006 to August 2008. Clinical criteria for suspected PCP were an acute onset of a respiratory illness, presence of age-specific tachypnoea and hypoxia, bilateral lung disease (not associated with wheezing) and a risk factor for PCP (HIV-infected, HIV-exposed, malnourished, receiving immunosuppressive therapy or immunodeficiency disease other than HIV). Patients were excluded if they had received treatment for PCP in the preceding 2 weeks or were on PCP treatment for more than 48 hours. A child was defined as HIV- infected if they had a positive HIV PCR (Amplicor HIV1 DNA test version 1.5, Roche Diagnostics GmbH, Mannheim, Germany) if younger than 18 months or a positive HIV ELISA (Architect HIV Ag/Ab Combo ELISA, Abbott Laboratories, Abbott Park, IL) in older children. HIV exposure in infants less than 18 months was defined as being HIV sero-positive with a negative HIV PCR. Children were treated according to a standard protocol for severe pneumonia that included intravenous co-trimoxazole and oral corticosteroids, as well as broad-spectrum antibiotics. Other antimicrobial therapy was added at the discretion of the attending clinician. Written informed consent was obtained from a parent or legal guardian. The study was approved by the Research Ethics Committee of the Faculty of Health Sciences at the University of Cape Town.

\section{Sample collection}

An upper respiratory tract sample (NPA) and a lower respiratory tract sample (IS in non-intubated patients or BAL in intubated patients) were obtained using standardised methods at the time of admission [11,22]. NPA specimens were obtained first, followed by LRT specimens. After routine laboratory investigations had been performed, an aliquot of sample was frozen at $-70^{\circ} \mathrm{C}$ for analysis by PCR.

\section{Control group}

Respiratory samples (NPA or BAL) from 30 children sequentially hospitalized with a confirmed viral LRT infection, who were randomly selected and who improved clinically without specific treatment for PCP, were investigated with PCR for PCP, as a control group.

\section{Laboratory investigations}

Direct immunofluorescence (IF) (Detect IF PC, AxisShield Diagnostics, Cambridgeshire, United Kingdom), to detect cystic forms of $P$. jirovecii using a monoclonal antibody immunofluorescent stain, was performed according to the manufacturer's instructions. Accordingly, results were reported as positive if more than 5 cysts were observed. In addition, Grocott's methenamine silver nitrate stain was performed on BAL specimens, as per clinician's request, if sufficient sample volume was available.

DNA was isolated using the Nuclisens EasyMAG platform (bioMérieux, Boxtel, Netherlands). P. jirovecii DNA was detected using a quantitative, touch-down, real-time PCR assay, targeting the major surface glycoprotein (MSG) gene as described by Larsen et al [13]. Commercially synthesized primers, amplifying a 250-bp segment of the multicopy MSG gene family, were utilized in a PCR reaction containing fluorescence resonance energy transfer (FRET) probes for detection of 
the amplified product [13]. The $P$. jirovecii MSG gene was cloned into the pCR 2.1 vector. Four external standards of the cloned target template, corresponding to $10^{6}, 10^{5}, 10^{4}$ and $10^{3}$ copies per microlitre, were used in each PCR run to generate an external standard curve, required for quantification. The reactions were performed on the LightCycler platform (Roche Diagnostics $\mathrm{GmbH}$, Mannheim, Germany) and results were calculated using the LightCycler software and expressed in copies/mL. A P. jirovecii positive and a negative control were included in each PCR run. Laboratory testing was conducted in an ISO-accredited molecular laboratory of the National Health Laboratory Service (NHLS) at Groote Schuur Hospital, Cape Town. The laboratory is designed with separate areas for DNA extraction, PCR preparation, DNA addition, and amplification, in order to reduce the chance of cross contamination. Use of a real-time PCR platform minimised the chance of contamination during the detection step. The investigators who performed the PCR testing were blinded to the IF or silver stain results.

\section{Data Analysis}

Statistical analysis was performed using statistical software Stata (version 10.0, StataCorp, Houston, USA). Continuous data was tested for normality using the Shapiro-Wilk test. Detection rates of PCR were compared by Pearson's chi-squared test and quantification results were compared by Wilcoxon rank-sum (Mann-Whitney) test. Paired analysis of continuous and binary variables was performed using $\mathrm{t}$ test and chi-squared test, respectively.

\section{Results}

\section{Patient characteristics}

212 children were enrolled (Table 1); 10 patients were excluded as there was insufficient respiratory sample left for PCR, thus 202 children were included in this analysis. Of these, $92(46 \%)$ were male; the median (IQR) age was 3.3 (2.2 - 4.6) months. HIV status was determined in 200 (99\%) patients, of whom 129 (65\%) were HIVinfected. Of the 71 (35\%) HIV-uninfected children, 32 (45\%) were HIV-exposed. Twenty-seven $(21 \%)$ of the $129 \mathrm{HIV}$-infected children were on co-trimoxazole prophylaxis at presentation. The median (IQR) CD4 percentage of HIV-infected children was $16.9 \%$ (10.1 - 27.1)

\section{PCR and IF on patient samples}

349 respiratory samples were obtained. One hundred and forty-seven (73\%) children had paired samples consisting of a NPA with either a BAL or IS. Fifty-five children produced a single respiratory sample (Table 2 ).

Real-time PCR performed on 349 respiratory samples detected $P$. jirovecii in 180 specimens (52\%) (Table 3). Of the 202 patients, 110 (54.5\%) had one or more specimens positive by PCR. The HIV status was determined in 109 of these 110 patients. 92 (84\%) of the 109 patients with a positive PCR result were HIV infected. This was significantly higher than in the total cohort of patients where $65 \%$ were found to be HIV-infected (Odds-ratio OR, 7.9; 95\% CI 3.9-16.3; p < 0.0001).

Overall, $P$. jirovecii DNA was detected in 37 of 66 (56\%) BAL specimens, 56 of 100 (56\%) IS and 87 of 183 (48\%) NPA. There was no significant difference between the detection by PCR on LRT samples compared to NPA (OR, 0.71; 95\% CI, 0.46 - 1.11; Table 3).

In contrast, $P$. jirovecii was detected by IF in $26(7 \%)$ of samples, consisting of 13 (50\%) BAL, 9 (35\%) IS and 4 (15\%) NPA samples. All 26 IF-positive samples were positive on PCR and thus no additional cases were detected using IF. The overall yield on upper tract samples was $48 \%(87 / 183)$ by PCR, as compared to the yield of $2 \%(4 / 183)$ by IF (OR 40.5; 95\% CI, 14.4-113.8; p < $0.0001)$. For lower tract samples, the yield from PCR was $56 \%(93 / 166)$ compared to $13 \%(22 / 166)$ by IF (OR 8.3; 95\% CI, 4.8-14.3; p < 0.0001).

$P$. jirovecii was also demonstrated on silver stain in 8 of the 25 (32\%) BAL samples sent for analysis. All 8 were also PCR positive, and 3 were IF positive. Of the 17 patients with a negative BAL silver stain, 5 (29\%) were PCR-positive and 3 were also IF positive.

\section{Comparison of yield by PCR on paired upper and lower respiratory tract samples}

Of the 147 paired upper and lower respiratory tract samples, 70 pairs were concordant PCR-positive, 63 pairs were concordant PCR-negative and 14 pairs had discordant PCR results. Of the discordant pairs, most

Table 1 Baseline characteristics of children admitted to hospital with suspected Pneumocystis jirovecii pneumonia

\begin{tabular}{lcc}
\hline Characteristic & All Patients $(\mathbf{n}=\mathbf{2 0 2})$ & Patients with positive PCR for PCP $(\mathbf{n}=\mathbf{1 1 0})$ \\
\hline Male & $92(46 \%)$ & $49(45 \%)$ \\
Median age, IQR, months & $3.3(2.2-4.6)$ & $3.4(2.7-3.9)$ \\
HIV positive & $129 / 200(65 \%)$ & $92 / 109(84 \%)$ \\
Median CD4 percentage*, IQR, \% & $16.9(10.1-27.1)$ & $13.6(9.0-18.0)$ \\
Cotrimoxazole prophylaxis* & $27(21 \%)$ & $1011 \%)$ \\
\hline
\end{tabular}

\footnotetext{
* In HIV-infected children
} 
Table 2 Sources of the 349 samples from 202 patients included in the study

\begin{tabular}{|c|c|c|c|c|}
\hline & \multirow{2}{*}{$\begin{array}{l}\text { Unpaired } \\
\text { Samples }\end{array}$} & \multicolumn{2}{|c|}{ Paired Samples } & \multirow{2}{*}{$\begin{array}{c}\text { Total } \\
\text { Samples }\end{array}$} \\
\hline & & $\begin{array}{l}\text { NPA } \\
+ \text { IS }\end{array}$ & $\begin{array}{l}\text { NPA } \\
+ \text { BAL } \\
\end{array}$ & \\
\hline NPA & 36 & 92 & 55 & 183 \\
\hline IS & 8 & 92 & - & 100 \\
\hline BAL & 11 & - & 55 & 66 \\
\hline $\begin{array}{c}\text { Total } \\
\text { Samples }\end{array}$ & 55 & 184 & 110 & 349 \\
\hline
\end{tabular}

URT, upper respiratory tract; LRT, lower respiratory tract; NPA, nasopharyngeal aspirate; IS, induced sputum; BAL, bronchoalveolar lavage

were PCR positive on the lower tract sample but negative on the upper tract sample (Table 4). Overall, the detection from upper and lower specimens by PCR was similar with 81 of 147 (55\%) lower respiratory tract samples positive by PCR vs. 73 of 147 (50\%) NPA samples (OR, 1.4; 95\% CI, 0.91-2.19). Only 8 (5\%) additional cases were detected by PCR when performed on a lower respiratory tract sample compared to a NPA specimen $(\mathrm{p}=0.11)$. Using a positive PCR result on a lower respiratory tract sample as a gold standard, the sensitivity, specificity, positive predictive value and negative predictive value for PCR on a NPA sample was $86 \%, 95 \%$, $96 \%$ and $85 \%$ respectively.

Concentrations of $P$. jirovecii DNA ranged from 3.2 to 9.4 $\log$ copies $/ \mathrm{mL}$. The median (IQR) organism load detected in NPA samples was significantly lower than that detected in lower respiratory tract samples [5.9 (5.4 - 6.7) log copies/ml compared to $6.6(5.8$ - 7.5) log copies/mL; $\mathrm{p}=0.0002$ ).

\section{Control group}

Of the 30 children in the control group, 18 (60\%) were male; the median (IQR) age was 6.0 (4.0 - 12.0) months. HIV status was determined in $21(70 \%)$ patients, of whom 2 (10\%) were HIV-infected, 6 (28\%) were HIV-exposed and 13 (62\%) were HIV-unexposed. Twenty-eight (93\%) of 30 control samples were PCR-negative. The 2 PCR positive samples (both NPA samples), were from HIV-unexposed infants, younger than 6 months old, with DNA concentrations of 6.1 and $6.7 \log$ copies $/ \mathrm{mL}$.

Table 3 Quantitative PCR and Direct IF performed on 349 respiratory samples collected from 202 patients

\begin{tabular}{lcccc}
\hline & $\begin{array}{c}\text { TOTAL } \\
(\mathbf{n}=\mathbf{3 4 9})\end{array}$ & $\begin{array}{c}\text { URT } \\
(\mathbf{n}=\mathbf{1 8 3})\end{array}$ & $\begin{array}{c}\text { LRT } \\
(\mathbf{n}=\mathbf{1 6 6})\end{array}$ & OR (95\% Cl) \\
\hline Positive PCR & $180(52 \%)$ & $87(48 \%)$ & $93(56 \%)$ & $0.71(0.46-1.11)$ \\
Positive IF & $26(7 \%)$ & $4(2 \%)$ & $22(13 \%)$ & $0.15(0.04-0.45)$ \\
\hline
\end{tabular}

URT, upper respiratory tract; LRT, lower respiratory tract; OR, Odds-ratio; $\mathrm{Cl}$, confidence interval; $P C R$, polymerase chain reaction; $I F$, immunofluorescence
Table 4 Real-time PCR results on paired upper and lower respiratory tract samples $(n=147)$

\begin{tabular}{cccc}
\hline & $\begin{array}{c}\text { LRT Sample } \\
\text { (IS/BAL) } \\
\text { Positive }\end{array}$ & $\begin{array}{c}\text { LRT Sample } \\
\text { (IS/BAL) } \\
\text { Negative }\end{array}$ & Total \\
\hline $\begin{array}{c}\text { URT Sample (NPA) } \\
\text { Positive }\end{array}$ & $70(48 \%)$ & $3(2 \%)$ & 73 \\
$\begin{array}{c}\text { URT Sample (NPA) } \\
\text { Negative } \\
\text { Total }\end{array}$ & $11(7 \%)$ & $63(43 \%)$ & 74 \\
& 81 & 66 & $140 \%)$ \\
\hline
\end{tabular}

URT, upper respiratory tract; LRT, lower respiratory tract; NPA, nasopharyngeal aspirate; IS, induced sputum; BAL, bronchoalveolar lavage

\section{Discussion}

This study found that PCR had a much higher sensitivity than the current standard diagnostic test of IF, with a more than 5 fold increased detection in upper and lower samples using PCR. In addition, an URT specimen was as reliable as a LRT specimen for PCR confirmed diagnosis. To our knowledge, this is the first study in children that demonstrates that $P$. jirovecii can be reliably detected using PCR on an upper respiratory tract specimen. The increase in diagnostic yield using PCR occurred in both upper and LRT specimens, but was especially marked in upper respiratory samples. This is important as obtaining a LRT specimen using BAL or IS in children can be difficult whereas obtaining a NPA is much easier, and carries a lower risk of nosocomial transmission of infection, thus making the diagnosis of PCP feasible in many health-care settings, including in primary care. The detection of organism in an URT sample may occur due to extension of infection to the upper airways in severe disease or by organisms that are propelled to the upper airway during coughing [16].

Using current methods of detection with staining, PCP may therefore be substantially under-diagnosed in children. This is supported by the low rates of laboratory confirmation of approximately $20 \%$ reported in clinical studies of children with suspected PCP [1,3]. When IF on LRT samples was used as the reference standard, the sensitivity of the PCR assay was $100 \%$.

A further advantage of PCR is the rapid turn-around time of the test, with results obtainable within hours. Children with PCP often have a rapidly progressive course, thus timely diagnosis would allow early initiation of treatment in those not on treatment, with potential reduction in mortality. The usual management of suspected PCP is empiric treatment with co-trimoxazole and corticosteroids in children who are hypoxic. Rapid confirmation of diagnosis would therefore also be useful for guiding corticosteroid therapy. This is especially relevant given the concerns about use of corticosteroids in other infections such as CMV pneumonitis or TB in children, without specific antimicrobial therapy for these 
pathogens $[23,24]$. The clinician may also consider discontinuation of co-trimoxazole therapy in patients with negative PCR results and contemplate alternative diagnoses.

The specificity of PCR for PCP is more difficult to determine as the organism cannot be cultured and there is no method to distinguish disease from asymptomatic colonization. The large number of IF-negative, PCR-positive samples may therefore represent children with PCP or with pneumocystis colonization. As all children were treated for PCP based on their clinical presentation, it was impossible to use response to therapy to distinguish active disease from colonization. The organism has been reported to colonize the airways of adults with chronic obstructive airway disease, with these individuals forming the reservoir for infection of susceptible hosts [25]. Moreover, positive PCR results have been reported in BAL samples from adults without clinical PCP, HIV, or other infections [26]. However, all children in the study had an underlying risk factor for PCP and were severely ill with a clinical presentation consistent with PCP. In addition most children were under 6 months of age, the highest risk period for primary PCP rather than colonization. It is, therefore, likely that a positive PCR result in these children represents disease.

To further investigate the specificity of PCR for PCP samples from 30 control children with confirmed viral LRT illness who improved clinically without therapy for PCP, were tested. In contrast to the detection rate in cases $(110,55 \%)$, only a minority $(2,6 \%)$ of control children were PCR positive. The 2 control positives may represent primary infection which is very common in children in the first years of life, and may manifest as a viral-like illness. Another possible explanation may be laboratory contamination. However, this is unlikely as the laboratory layout allows only unidirectional workflow with strict separation of all steps in the PCR process. The real-time PCR was performed in a closed system, with detection occurring on the same platform thus minimizing the risk of contamination.

An alternative strategy for differentiating colonization from disease is by applying cut-off values to quantitative PCR results. Huggett et al were able to achieve a specificity of $96 \%$ in BAL specimens from adult patients by using a quantitative PCR for HSP70, with appropriate cut-off values [27]. Unfortunately, the quantitative results obtained in our study could not be accurately interpreted as data was not normalized by use of a reference gene as an internal control. Normalization may control for variations in the extraction process, patient variability and inter-sample variability by accounting for the dilution factor in the BAL fluid. However, there is controversy about the choice of the most appropriate reference gene [28]. If normalization can be reliably performed, it may allow for more accurate estimation of colonization rates and of cut-off values to distinguish disease thus improving the specificity of the assay. Further work in this area is needed.

Potential difficulties in achieving widespread implementation of PCR for PCP diagnosis include cost and the need for a specialized molecular laboratory, equipment, and personnel. However, much progress has been made in developing closed molecular amplification platforms for the diagnosis of TB at point-of-care facilities. Given the scale of the HIV pandemic and the substantial mortality associated with PCP particularly in children, a similar approach for the diagnosis of PCP, should be undertaken.

\section{Conclusion}

In summary, this real-time PCR-based assay has a much higher sensitivity than current diagnostic tests and allows for the use of a NPA sample for reliable detection of $P$. jirovecii in children. PCR on a NPA should replace the traditional diagnostic method of IF or silver stain performed on LRT samples. The possibility of making a reliable diagnosis on a NPA represents an important advance in confirming PCP in children. Widespread implementation of this technology is needed especially in high burden HIV and resource limited settings.

\section{Acknowledgements}

This research was supported by an NHLS Research Trust grant; the National Research Foundation, South Africa; ASTRA-Zeneca Respiratory Award from the South African Thoracic Society and the Medical Research Council of Southern Africa. We thank Louise LeSai for her assistance with enrolling patients; Sandra Hainsworth and Charmaine Barthus for their assistance in sample collection and processing; and Lemese Ah-Tow and Jane Parsons for their assistance in the molecular laboratory. Joe Kovacs is gratefully acknowledged for supplying the plasmid DNA.

\section{Author details}

'Division of Medical Microbiology, University of Cape Town and National Health Laboratory Service, Cape Town, South Africa. ${ }^{2}$ Division of Clinical Virology, University of Cape Town and National Health Laboratory Service, Cape Town, South Africa. ${ }^{3}$ Department of Paediatrics and Child Health, University of Cape Town, Red Cross War Memorial Children's Hospital, Cape Town, South Africa.

\section{Authors' contributions}

$\mathrm{HZ}$ was responsible for study conception and design, clinical supervision and obtained funding. AW was the laboratory supervisor, contributed to the study design and obtained funding. CC assisted in setting up the molecular assay. BM and MZ recruited patients and acquired data. $\mathrm{MH}$ assisted in the statistical analysis. CS was the project leader in the laboratory, performed the molecular investigations and is first author of the manuscript. All authors contributed to the final manuscript and have read and approved of it.

\section{Competing interests}

The authors declare that they have no competing interests.

Received: 17 August 2011 Accepted: 28 November 2011 Published: 28 November 2011

\section{References}

1. Zar HJ, Dechaboon A, Hanslo D, Apolles P, Magnus KG, Hussey G: Pneumocystis carinii pneumonia in South African children infected with human immunodeficiency virus. Pediatr Infect Dis J 2000, 19(7):603-7. 
2. Chintu C, Mudenda V, Lucas S, Nunn A, Lishimpi K, Maswahu D, Kasolo F, Mwaba P, Bhat G, Terunuma H, Zumla A, UNZA-UCLMS Project Paediatric Post-mortem Study Group: Lung diseases at necropsy in African children dying from respiratory illnesses: a descriptive necropsy study. Lancet 2002, 360:985-90.

3. Graham SM, Mtitimila El, Kamanga HS, Walsh AL, Hart CA, Molyneux ME: Clinical presentation and outcome of Pneumocystis carinii pneumonia in Malawian children. Lancet 2000, 355(9201):369-73.

4. Ruffini DD, Madhi SA: The high burden of Pneumocystis carinii pneumonia in African HIV-1 infected children hospitalized for severe pneumonia. AIDS 2002, 16(1):105-112.

5. Morrow BM, Hsaio NY, Zampoli M, Whitelaw A, Zar HJ: Pneumocystis pneumonia in South African children with and without human immunodefiency virus infection in the era of highly active antiretroviral therapy. Pediatr Infect Dis J 2010, 29(6):535-9.

6. Madhi SA, Cutland C, Ismail K, O'Reilly C, Mancha A, Klugman KP: Ineffectiveness of trimethoprim-sulfamethoxazole prophylaxis and the importance of bacterial and viral coinfections in African children with Pneumocystis carinii pneumonia. Clin Infec Dis 2002, 35(9):1120-6.

7. Durand-Joly I, Chabé M, Soula F, Delhaes L, Camus D, Dei-Cas E: Molecular diagnosis of Pneumocystis pneumonia. FEMS Immunol Med Microbiol 2005, 45(3):405-410.

8. Kovacs JA, Ng VL, Masur H, Leoung G, Hadley WK, Evans G, Clifford Lane $H$, Ognibene FP, Shelhamer J, Parrillo JE, Gill VJ: Diagnosis of Pneumocystis carinii pneumonia: improved detection in sputum with use of monoclonal antibodies. N Engl J Med 1988, 318(10):589-593.

9. Turner D, Schwarz Y, Yust I: Induced sputum for diagnosing Pneumocystis carinii pneumonia in HIV patients: new data, new issues. Eur Respir J 2003, 21(2):204-8.

10. Zar HJ, Tannenbaum E, Hanslo D, Hussey G: Sputum induction as a diagnostic tool for community-acquired pneumonia in infants and young children from a high HIV prevalence area. Pediatr Pulmonol 2003, 36(1):58-62.

11. Alvarez-Martínez MJ, Miró JM, Valls ME, Moreno A, Rivas PV, Solé M, Domingo P, Munoz C, Rivera E, Zar HJ, Wissmann G, Diehl AR, Prolla JC, de Anta MT, Gatell JM, Wilson PE, Meshnick SR: Sensitivity and specificity of nested and real-time PCR for the detection of Pneumocystis jirovecii in clinical specimens. Diagn Microbiol Infect Dis 2006, 56(2):153-160.

12. Tamburrini E, Mencarini $P$, Visconti E, Zolfo M, Marinaci S, Zinzi D, Margutti P, Ortona E, Siracusano A: Potential impact of Pneumocystis genetic diversity on the molecular detection of the parasite in human host. FEMS Immunol Med Microbiol 1998, 22(1):37-49.

13. Larsen HH, Masur H, Kovacs JA, Gill VJ, Silcott VA, Kogulan P, Maenza J, Smith M, Lucey DR, Fischer SH: Development and evaluation of a quantitative, touch-down, real-time PCR assay for diagnosing Pneumocystis carinii pneumonia. J Clin Micro 2002, 40(2):490-494.

14. Fischer S, Gill VJ, Kovacs J, Miele P, Keary J, Silcott V, Huang S, Borio L, Stock F, Fahle G, Brown D, Hahn B, Townley E, Lucey D, Masur H: The use of oral washes to diagnose Pneumocystis carinii pneumonia: a blinded prospective study using a polymerase chain reaction-based detection system. J Infect Dis 2001, 184(11):1485-1488.

15. Brancart F, Rodriguez-Villalobos H, Fonteyne PA, Peres-Bota D, Liesnard C: Quantitative TaqMan PCR for detection of Pneumocystis jiroveci. $J$ Microbiol Methods 2005, 61(3):381-387.

16. Nyamande K, Lalloo UG, York D, Naidoo M, Irusen EM, Chetty R: Low sensitivity of a nested polymerase chain reaction in oropharyngeal washings for the diagnosis of pneumocystis pneumonia in HIV-infected patients. Chest 2005, 128(1):167-71.

17. Palladino S, Kay I, Fonte R, Flexman J: Use of real-time PCR and the LightCycler system for the rapid detection of Pneumocystis carinii in respiratory specimens. Diagn Microbiol Infect Dis 2001, 39(4):233-236.

18. Flori P, Bellete B, Durand F, Raberin H, Cazorla C, Hafid J, Lucht F, Sung RT: Comparison between real-time PCR, conventional PCR and different staining techniques for diagnosing Pneumocystis jiroveci pneumonia from bronchoalveolar lavage specimens. J Med Microbiol 2004, 53:603-607.

19. Ribes JA, Limper AH, Espy MJ, Smith TF: PCR detection of Pneumocystis in bronchoalveolar lavage specimens: analysis of sensitivity and specificity. J Clin Microbiol 1997, 35(4):830-835

20. Olsson $\mathrm{M}$, Stralin $\mathrm{K}$, Holmberg $\mathrm{H}$ : Clinical significance of nested polymerase chain reaction and immunofluorescence for detection of Pneumocystis carinii pneumonia. Clin Microbiol Infect 2001, 7(9):492-497.
21. Wakefield AE, Miller RF, Guiver LA, Hopkin JM: Oropharyngeal samples for detection of Pneumocystis carinii by DNA amplification. Q J Med 1993, 86(6):401-406

22. Morrow B, Futter M, Argent A: A simple method of reducing complications of pediatric nonbronchoscopic bronchoalveolar lavage. Pediatr Pulmonol 2004, 38(3):217-221.

23. Jensen AM, Lundgren JD, Benfield T, Nielsen TL, Vestbo J: Does cytomegalovirus predict a poor prognosis in Pneumocystis carinii pneumonia treated with corticosteroids? A note for caution. Chest 1995 108(2):411-1.

24. Jeena PM, Coovadia HM, Chrystal V: Pneumocystis carinii and cytomegalovirus infections in severely ill, HIV-infected African infants. Ann Trop Paediatr 1996, 16(4):361-8.

25. Helweg-Larsen J, Jensen JS, Dohn B, Benfield TL, Lundgren B: Detection of Pneumocystis DNA in samples from patients suspected of bacterial pneumonia-a case-control study. BMC Infect Dis 2002, 2:28.

26. Maskell NA, Waine DJ, Lindley A, Pepperell JC, Wakefield AE, Miller RF, Davies RJ: Asymptomatic carriage of Pneumocystis jiroveci in subjects undergoing bronchoscopy: a prospective study. Thorax 2003, 58(7):594-7.

27. Huggett JF, Taylor MS, Kocjan G, Evans HE, Morris-Jones S, Gant V, Novak T, Costello AM, Zumla A, Miller RF: Development and evaluation of a realtime PCR assay for detection of Pneumocystis jirovecii DNA in bronchoalveolar lavage fluid of HIV-infected patients. Thorax 2008, 63(2):154-9.

28. Etoh K: Evaluation of a real-time PCR assay for the diagnosis of Pneumocystis pneumonia. Kurume Med J 2008, 55(3-4):55-62.

\section{Pre-publication history}

The pre-publication history for this paper can be accessed here: http://www.biomedcentral.com/1471-2334/11/329/prepub

doi:10.1186/1471-2334-11-329

Cite this article as: Samuel et al:: Improved detection of Pneumocystis jirovecii in upper and lower respiratory tract specimens from children with suspected pneumocystis pneumonia using real-time PCR: a prospective study. BMC Infectious Diseases 2011 11:329.

\section{Submit your next manuscript to BioMed Central and take full advantage of:}

- Convenient online submission

- Thorough peer review

- No space constraints or color figure charges

- Immediate publication on acceptance

- Inclusion in PubMed, CAS, Scopus and Google Scholar

- Research which is freely available for redistribution

Submit your manuscript at www.biomedcentral.com/submit
C Biomed Central 